\title{
Entrevista a William H. Newell
}

por Maria Clara Paulino

A entrevista ocorreu em diferentes momentos entre 23 de julho e 3 de agosto de 2017.

William H. Newell é autor e editor de obras importantes no campo dos estudos interdisciplinares, entre as quais Case Studies in Interdisciplinary Integration (2011), bem como de muitas dezenas de artigos e ensaios que, ao longo de décadas, têm estruturado os princípios metodológicos da investigação e pedagogia interdisciplinares. Entre estes destacam-se, pelo impacto que tiveram no mundo académico, "The State of the Field: Interdisciplinary Theory" e "Contributions of Interdisciplinary Studies to Civic Learning: An Addendum to A Crucible Moment", ambos publicados, em 2013, na revista Issues in Interdisciplinary Studies da Associação de Estudos Interdisciplinares dos Estados Unidos.

Newell foi diretor do Institute in Integrative Studies e professor de Estudos Interdisciplinares na Universidade de Miami-Oxford até 2012, ano em que se reformou. Desempenha, desde há duas décadas, as funções de avaliador externo de programas interdisciplinares em universidades americanas. Mais recentemente, em 2015, avaliou os programas da Universidade Plymouth State, em New Hampshire, e da Universidade DePaul, em Chicago. 
MCP: How do you define interdisciplinarity? Is it a method, a process, an "approach, " a point of view, or a full discipline with its own epistemology? Are you aware of other possible definitions?

WHN: Back in the mid to late 1990s, Julie Klein and I published an emerging consensus definition of IDS [Interdisciplinary Studies] in a major revision of the Handbook of the Undergraduate Curriculum, published by the Association of American Colleges \& Universities. Basically, this 1997 definition was an amalgamation and codification of the key elements of often-implicit working definitions of IDS we each encountered on campuses where we had consulted in the 1990s. The definition: IDS is a process of answering a question, solving a problem, or addressing a topic that is too broad or complex to be dealt with adequately by a single definition or profession. IDS draws on disciplinary perspectives and integrates their insights into a more comprehensive perspective. The details of this definition have been tweaked ever since, but its basic approach and structure are widely accepted these days among teachers of interdisciplinary courses in the U.S., and increasingly in the E.U. If I were to revise it today, I would a) refer to an "issue" rather than a "topic," to narrow the focus so disciplines have to confront their differences and not get away with talking past each other; 2) eliminate breadth as a rationale for IDS and refer exclusively on complexity, because I've seen fully interdisciplinary work that is quite narrowly focused, and very broad scholarship that wasn't fully interdisciplinary; 3) say that IDS "works towards the integration of their insights" rather than "integrates their insights" in deference to the humanities and especially the fine and performing arts, which see their mission as raising questions and provoking rather than supplying answers and enlightening; and 4) take as the goal of interdisciplinary work the construction of an understanding, not a perspective, that is more comprehensive. For two reasons: One, it helps clarify the distinctive yet complementary contributions of IDS from those of TDS [Transdisciplinary Studies] to say it seeks understanding whereas the latter seeks implementation, and two, I have come to see "understanding" as ever-modified in light of new insights (which IDS is) whereas perspectives are resistant to change. 
You quite appropriately ask whether IDS is a process-as the Klein-Newell definition claims-or a method, approach, point of view, or discipline. All of these terms (indeed, interdisciplinary studies itself) were developed within the context of Western culture's discipline-dominated approach to academic scholarship. It should be no surprise, then, that each of these terms gets at one or more aspects of IDS but none of them adequately capture it in its entirety.

I've often thought that interdisciplinary studies might be more accurately (if less felicitously) called interperspectival studies, because it need not limit the sources of insight from which it draws to academic disciplines. Richard Carp ${ }^{1}$ contends it should pay as much attention to folk or experiential knowledge, and transdisciplinarians emphasize the importance of stakeholders as sources of insight. I also think that it's more appropriate to refer to IDS methodology rather than method. Many methods, often drawn from disciplines, are utilized in carrying out IDS process. One could (indeed, I have) refer to the interdisciplinary approach or methodology in contrast to an overall disciplinary approach or methodology. The trouble is, IDS is as much about drawing from disciplines as it is about integrating their insights. IDS, if you will, routinely commits serial disciplinarity. It is both of the disciplines and a meta-level over them.

One could casually dismiss the claim that IDS has a point of view of its own by pointing out that it draws without prejudice or preference from whatever points of view claim to have insight into the object of inquiry. While that's true, it's also fair to say that IDS embodies values such as intellectual balance, mental flexibility, open-mindedness, diversity of perspective, thinking holistically as well as dualistically, contextually and systemically, etc. It's largely a liberal enterprise.

Thinking of IDS as process most clearly distinguishes it from disciplines, which typically carve out a subject matter in which they specialize. IDS deals with any subject matter that is an aspect of a particular complex phenomenon, problem, issue, or question which interdisciplinarians wish to study.

Finally, you raise a much-debated question about IDS as a whole. Should we think of it as a discipline, a profession, or a hybrid of the two? For me the answer involves strategy 
as much as accurate depiction. I think all interdisciplinarians believe IDS should be viewed with at least as much respect as the disciplines, and those of us in the Association for Interdisciplinary Studies [AIS] would like to see it practiced with as much discipline as are the disciplines. Yet, it transcends the disciplines as much as it draws on them. And its purview potentially encompasses all the disciplines and any of their subject matter, as long as the object of study is complex. On the other hand, it draws on disciplines as the professions do-more so, even, while applying their insights to subjects that transcend the purview of disciplines. Yet, unlike transdisciplinarity, IDS lacks an applied focus. IDS can be every bit as academic and "ivory tower" as the disciplines. But if we think of IDS as some unique hybrid, there's no place for it on the organizational chart of universities. Or it gets shuffled off to some corner like a Center for the Study of [X] when many advocates of IDS believe it is central to the mission of universities, deserving more prominence, not less. AIS has chosen to refer to IDS as a profession. I2S [Integration \& Implementation Sciences] prefers to think in terms of a discipline. I anticipate that the answer to this question will need to shift as institutions of higher education evolve.

MCP: Coming from the humanities, it strikes me that you seem not to have thought about the arts and the humanities as somehow part of the equation, at least in the beginning. Am I right?

WHN: Well, I didn't include them because I was not sufficiently familiar with them and I wanted to make sure I was doing it right. In fact, at first I wasn't doing it very well at all and I am slowly starting to improve.

MCP: It's an interesting point because whereas you can define pretty well what the object of economics is, or what the discipline is about, when it comes to art history, for example, things seem a little more fluid.

WHN: Yes, I think so, at least as far as I understand it.

MCP: Art history brings in visual image, history, sociology, and so on. On a different but 
related note, the reason I was invited to take on the role of director of a degree in Interdisciplinary Studies, as you know, was that my background includes different academic tracks, namely literature and art history. But I never felt that this, in itself, prepared me to take on interdisciplinary studies. I had to grapple with the question of what makes something, or someone, interdisciplinary rather than an amalgam of disciplines. In many cases, that's what a department of Interdisciplinary Studies is: a place where minors and special topics are gathered, with no attempt at integration.

WHN: Certainly, breadth of interest would be a help and familiarity with more than one perspective, maybe even several, is really helpful. But, as I've come to understand interdisciplinary studies, it's really about working towards understanding a complex phenomenon or problem or situation. And the very fact that you can look at that phenomenon from multiple perspectives, just because you have multiple perspectives at your disposal, does not necessarily mean that you will in fact use them or even all the appropriate ones in trying to understand a particularly complex phenomenon. You probably will, but you might not. What it really sets you up for is a multidisciplinary approach. What distinguishes that, of course, from interdisciplinary studies is the integration. And people who have diverse intellectual backgrounds sometimes have used those in the service of integrating insights from them, and other times that's quite foreign and they compartmentalize. They use this skill in this situation and that skill in that situation, this way of looking at it, that way of looking at it, and they don't think in terms of integrating what they learned from those diverse perspectives.

MCP: Quite, integration is the key. How do you define integration? How do you know whether integration is actually happening, or whether the approach is multidisciplinary?

WHN: That's a very good question. There's not going to be a single nice neat answer to it. If you come out with an understanding that clearly draws in some way on each of the perspectives that claim to have major insights into that phenomenon or problem, and if that understanding is not dominated by any one of them, then that is, I would say, the gold standard for judging that you have achieved integration. Other people will talk about 
coming up with a whole that's larger than the sum of its parts, and I agree with that on the abstract theoretical level but I don't think it's very helpful at the applied level, when you're actually looking at a particular exercise in interdisciplinary research. The test that I just gave you, I think, is more functional; it works better. I should add that just because it's a fully interdisciplinary integration does not necessarily mean that it's the right one.

\section{MCP: Could you elaborate on that?}

WHN: Well, in the social and natural sciences, if it leads to, say, policy or lines of inquiry that get policy that works better than other policies, or lines of research that prove to be more fruitful than the lines that were being employed before, then I would say it's better, if not best. In the humanities and the fine and performing arts, I would say that if a line of enquiry leads viewers or listeners or voyeurs or whatever to respond in ways that are more functional, that address whatever issues the artist thinks she or he is addressing, then that's better than others that don't. In short, what I am saying is that the proof of the pudding is in the eating.

MCP: As you were speaking, I realized that you often place an emphasis on understanding and insight. I believe this is important because for many disciplines that is the goal; they don't necessarily aim at implementation.

WHN: Yes, one could say that in the humanities expression is important, or provocation, instead of understanding. But to me those are indirect forms of understanding. They are designed to move the process along towards understanding. That's what the authors claim to be able to do and the audience is drawn in in a way that leads them to engage and to better understand an issue. I see those branches of knowledge as working indirectly, behind the scenes. Now there are plenty of cases in which art is really not about addressing anything that's complex, it's simply about beauty. That has no bearing that I can see on what I am talking about.

MCP: An interesting line of enquiry in itself, I think. I would argue that questions 
around beauty are extremely complex, in fact, and do have a bearing on everything because they may provide insights on many levels simultaneously.

WHN: Why don't you write that up for an article?

MCP: I might. But I'm trying to make sure I understand what you said earlier about the humanities and the arts not working towards enlightenment; that you see their mission as raising questions and provoking rather than enlightening. How are you using the concept of enlightenment here?

WHN: Enlightening meaning understanding. I should add that in reference to the humanities and especially the fine and performing arts, the emphasis is on the notion of "working towards" instead of just integrating. Integration is very important in these fields if you think in terms of research teams, or if you think in terms of any one person's interdisciplinary research contributing to a larger effort, even if it's through the scholarly literature over time. And I don't want to say that the only way that you qualify as having done fully interdisciplinary work is if you do the whole damn thing yourself. It's everyone's contribution that is designed to and, in fact, does move us along collectively, whether the team or humanity, towards a better understanding or a more comprehensive understanding of complex phenomena or problems. Then that counts as fully interdisciplinary work.

MCP: I wonder if you could be specific as to how the interdisciplinary process contributes to cognition differently than the multidisciplinary process. Are interdisciplinary approaches compatible with transdisciplinary ones? How would an interdisciplinary research project work with, say, gender studies, or post-colonial studies?

WHN: MDS [Multidisciplinary Studies] draws insights from disciplines, much as IDS and TDS do, but it makes little if any attempt to integrate those insights as IDS does or apply them as TDS does. It's often said that MDS is content with mere juxtaposition of insights, and that's correct as far as it goes. But the focus of MDS is not necessarily on matters complex, nor on concerns public. In fact, the de facto concern of MDS is often with finding 
connections within a general subject matter area, not with a focused problem, issue, or question. It often strikes me as a fishing expedition, not an exercise in problem-solving.

TDS differs from IDS in several important respects. As I mentioned earlier, it pays relatively more attention to application than it does to understanding (and IDS does the converse). It draws non-academic parties (stakeholders such as interest group representatives, politicians/policy-makers such as mayors or agencies, and policy implementers such as public administrators) into the process of integrating insights into a more comprehensive understanding (so that the resulting understanding is actionable). And it tends to draw insights based on personal experience of affected populations, not just on disciplines.

The differences in cognitive impact between MDS and IDS derive from the fact that by limiting itself to drawing insights from disciplines and identifying random connections, MDS misses out on the development of educational outcomes that IDS promotes through explicit attention to integration (which is itself recognized as a higher-order thinking skill). These outcomes are: a strong-sense critical thinking (in which the critical gaze is turned inwards); balanced thinking-judgment; comfort with ambiguity-move from tolerating it to seeking it out; demythologizing/critically assessing experts and expertise; and empowerment to address complex real-world issues.

Furthermore, I see IDS and TDS as fully complementary. I'm not so sure the pragmatic, politicking, organizational skills required to fulfill the applied goals of TDS can often be found in scholars who excel at the intellectual and cognitive skills required to fulfill the understanding goals of IDS. Certainly it's rare to see IDS scholarship that does a good job of taking account of the real world challenges of implementation, and it's equally rare to see TDS projects that pay much attention to the intellectual and cognitive challenges of interdisciplinary integration. (I readily admit that I am loath to address the messy challenges of implementation, while I revel in addressing the cognitive/intellectual challenges of IDS integration.) So IDS and TDS need each other.

MCP: Our time is coming to an end and I'd like to make sure we address the question of 
disciplinary identity. How much do disciplines have to "lose," or to give up, when they engage with other disciplines with the purpose of reaching an interdisciplinary solution? Is a discipline ever in danger of losing its identity?

WHN: As an interdisciplinarian who sees complexity as the raison d'être for IDS, I'm a big fan of the disciplines. Far from wanting to see them lose their identity, I want to see them thrive. That's because I see disciplines (roughly) specializing in different aspects of reality, and each of those aspects operating according to somewhat different rules, principles, and laws. In this view (which is not without its critics from several sides), the distinctive operations of the biological, physical, and geological aspects of the natural world, the distinctive operations of the psychological, economic, political, social, cultural, and religious aspects of the human world, and so on for the imaginative worlds of the humanities and fine/performing arts, all justify distinctive characteristics of the disciplines studying them.

What I am NOT a big fan of is disciplinary hubris. The success of disciplines in explaining or interrogating their domain of inquiry tends to lead them to delusions of grandeur. My home discipline of economics is a prime example of an overweening sense of self-importance that leads its members to believe they can explain just about any human behavior better than the discipline specializing in that area. But every discipline seems to harbor the belief that it is at least the first among equals.

IDS needs the disciplines to retain distinctive characteristics that reflect the distinctive features of the aspect of reality they study. Only then can they adequately understand that aspect, so the tension between disciplinary perspectives brings out the real-world tensions between the aspects they study. But IDS also needs the disciplines to recognize and accept their limitations, so they can contribute to IDR without undermining it at the same time.

I'd like to note that in my consulting trips (numbering well in excess of a hundred) to colleges and universities in North America alone, I have frequently encountered faculty members who report they can no longer teach their disciplinary courses as they used to after teaching an IDS course a few times. It's not that they have lost their disciplinary 
identify; they merely see their discipline in a larger context. They are more aware of the limitations of its often-implicit assumptions, and they have a better sense of what's distinctively valuable in their discipline and hence what they should emphasize in their teaching.

MCP: I couldn't agree more with your position regarding disciplines and their importance in the interdisciplinary process. It's crucial that they understand their own domains. The problem arises, as you say, when they think that their domains are the only ones capable of explaining complex phenomena. I often wonder whether there are times when disciplines have to function in a very "closed" way, if you will -- for example, when they are making strides in very specific areas -- and times when they are ready to take stock, get perspective, and work with other disciplines. Is there an ebb and flow?

WHN: This is an art historian talking about disciplines, I can tell. There is an element of intellectual history where you're seeing a long-term ebb and flow in a disciplinary culture, if you will.

MCP: This seems to be a time when the need for interconnectedness arises as questions become more and more complex.

WHN: It's undeniable that they are more complex. And yes, there is more of a need that will only grow more so in the future because of forces like globalization. There's a need for connecting the world, the planet, and all human cultures in ways that lead to complexity. So yes, from now on we're are going to need some kind of back and forth between disciplinarity and interdisciplinarity, each supporting, bootstrapping even, the other. But you are raising a question that goes beyond that, which is the long-term trends in the development of any one discipline, and I can see your point about forging ahead and then taking stock; and then the question is, where will interdisciplinary studies fit into that? Will it play a role in those long-term cycles within disciplines? I'm guessing that it will, in the following way. This is just a guess: Maybe interdisciplinary studies will help disciplines decide between competing paradigms within the discipline, because one paradigm may not 
connect as well with the rest of academia, while others do. I think about psychology, for example B. F. Skinner's work, which was in Behaviorism. When I was coming of age intellectually, it was all the rage in psychology, and Skinner is one of the people I have been thinking about as I talk with you. He basically felt that he could subsume all of the social sciences under the principles that he was developing. And if there had been interdisciplinary studies then as we have it now, and people from other disciplines were working with psychologists, I think they would have quickly picked up on the fact that there are limits to the effectiveness of what they were saying and they would not have gone so full bore towards "operant conditioning" and so on. I do think that "operant condition" plays a role, by the way.

MCP: Going back to the need for interdisciplinarity in a world that is ever more global and complex, how do you see the role of academia in all of this? Is the academic environment attuned and responsive? Often it seems that industries, corporations, and professional institutions are more engaged with interdisciplinarity than we are.

WHN: There is a huge move towards interdisciplinarity in medicine. And there's more and more research being done in the natural sciences that has at least an interdisciplinary component to it. It's the scientists who are trying to figure out how to train the next generation of scientists so they can better participate in team science. But the problem is that they're not paying much attention, to put it mildly, to the work on interdisciplinary studies that's coming out of interdisciplinary teaching, which is where AIS comes from. And getting them to realize that there are all kinds of issues that they're not even paying any attention to that do have a big effect on their potential outcomes is a real challenge, no question at all.

I really can't speak for the Humanities or Fine and Performing Arts because they seem to me to be so disconnected, deliberately pulling themselves away from pragmatic considerations; they think they are above them in some way, which I find extraordinarily disappointing because I think they have so much to contribute. We really need people who point out that there's a values dimension to this [the Humanities and Fine and Performing 
Arts], an aesthetic dimension, a religious dimension, which are being ignored. But in the social sciences, there's certainly a tendency towards more interdisciplinary work than there used to be. There's a whole division of the National Science Foundation [NSF], the social behavioral economic division, that's trying to promote interdisciplinary work in the social sciences. The trouble is that, again, they're not paying any attention to what we've learned about interdisciplinary studies. So there is IDR and IDS, two totally separate enterprises: IDR can't be bothered to even look at IDS. Julie T. Klein has been banging her head against that wall for years. And sometimes some people will listen and will make a little bit of progress but it's very slow. So, I think that's the problem, more so than the disciplines themselves being opposed to it. In fact, I am seeing more and more disciplines, political science for example, that claim they do interdisciplinary work. You just made an argument art historians do that. Historians have made that argument, sociologists have made that argument, and anthropologists have made that argument. The trouble is again, in every case, that they're not actually looking at what's entailed in doing interdisciplinary work.

MCP: Having had experience teaching both art history and interdisciplinary studies, I've realized that art history, just to use an example I know well, is most often -- and at best -taught as a multidisciplinary field, not interdisciplinary. But my question, and this would be the last, is this: Is it a good idea, and would it be feasible, to include at least one course on interdisciplinary methodologies in the required curriculum for all college students?

WHN: Well, that's what I'm working out right this minute. That's been my goal since the early '80s. I wrote an article on the role of interdisciplinary studies then. I think it was on liberal education, and I was making that argument then. And I've been working towards that in the last couple of years in retirement. Especially after I stepped down as AIS executive director, I've been focusing my energies on persuading my alma mater, Amherst College, to revise their "curriculum," which is by any standard definition not a curriculum at all but a collection of courses in various disciplines and a bunch of major disciplinary courses that are kind of floating around that students might or might not take. I'm arguing that they should have a set of three required interdisciplinary core courses that give every 
single student, whether they're heading into law or medicine or diplomacy or some esoteric field within physics. Courses for everybody, in preparation for being a citizen of the Twenty-first century. And to have enough exposure to the interdisciplinary approach, the interdisciplinary process, so that they can function in an increasingly complex world. I've been working with a group of my classmates, the class of '65, and amazingly enough we've been making a lot of progress. It's not a done deal, but we are going much, much further than I ever thought was going to be possible. I tried doing something like this back, maybe 15 years ago, and I got nowhere. But by working with my classmates, a group of four who are interested in core experiences and interdisciplinary approaches, we now have the ear of the board of trustees and their strategic plan, of the provost, the dean of the faculty, and the faculty curriculum committee. My reason for focusing on it so much at Amherst is in part because it's my alma mater and I have a way in, but also because it is one of, if not the premier elite small private liberal arts college in the United States. If they adopt a series of required interdisciplinary courses, and do it along the lines of what you and I understand interdisciplinary studies to be, other institutions are going to take a really close look at that and I suspect we might start to have a whole line of dominoes falling. So yes, I agree with you completely, and that has been my main thrust of my work over the past decades since the 1970 s.

MCP: I can only congratulate you on the effort. I believe strongly in the value of these methods to move towards an interdisciplinary understanding, perhaps a different way of seeing.

WHN: You can focus on a way of looking, you can focus on habits of mind, you can focus on process. You can list a number of different ways of conceptualizing interdisciplinarity that are complementary and overlapping. The way my mind works, it is process that makes sense to me. For some people, it's too rigid; for me, it's more precise.

MCP: We've come to the end of our time. I wish I didn't have to go because now I have many other questions. It's been such a pleasure talking with you. I hope your efforts at 
Amherst succeed and have a much-needed domino effect.

WHN: I have enjoyed talking with you too. Let me know if you want to continue at some other time.

\section{Note}

${ }^{1}$ Carp, Richard (2008). "Seeing is Believing, but Touching's the Truth: Religion, Film, and the Anthropology of the Senses", Teaching Religion and Film, Oxford University Press; (2008). "Art, Education, and the Sign(ificance) of the Self", Semiotics and Visual Culture: Sights, Signs, and Significance, National Art Education Association; (2010). "Resilient Religion: Media, the Senses, and Religion in Postcolonial Postmodernity - Aesthetic Formations: Media, Religion, and the Senses, The Senses and Society. ed. Birgit Meyer. 5. 263-265, Taylor and Francis online. 